Journal of Universal Language 15-2

September 2014, 35-54

\title{
The Syntax of Po Tangle Numerals
}

\author{
Mary Chimaobi Amaechi \\ University of Ilorin, Nigeria
}

\begin{abstract}
This paper examines the endangered numerals of Po Tangle [tangle], a minority language spoken in four local government areas in Gombe State, north eastern Nigeria. The emphasis is on the cardinal whole numbers. The study explores the structure of complex numerals which are derived from simple lexical ones using syntactic coordination and complementation. The study adopts the packing strategy framework of Hurford (1975, 1987, 2003, 2007). This framework adopted applies very widely to numeral systems that uses syntactic constructions to signal multiplication and addition. It is found out that there is no overt marker for multiplicative arithmetic operation but there are two distinct markers for additive arithmetic operation, salai and $k a$, while the former is used for lower complex numerals in the base of ten, the latter is found in higher complex numerals of bases hundred and thousand.
\end{abstract}

Keywords: Po Tangle, numeral, packing strategy, syntax, connectives, phrase structure rules

\footnotetext{
Mary Chimaobi Amaechi

Department of Linguistics and Nigerian Languages, University of Ilorin

P.M.B. 1515, Ilorin, Nigeria

Phone: +2348066392599; Email: mumemay@gmail.com
}

Received June 12, 2014; Revised July 30, 2014; Accepted August 28, 2014. 


\section{Introduction}

In everyday life, human beings use numbers to make reference to time, quantity, distance, weight, height, and so on. It is the case that the numeral systems of most of the world's languages are more endangered than the languages themselves. Young people and even adults who have a high level of proficiency in their mother tongue find it difficult to recite the conventional sequence of their languages' numerals. A numeral system according to Hurford (2001) is a part of a natural language primarily devoted to the expression of positive whole numbers. In everyday life, people make use of numbers to make reference to age, time, size, quantity, weight, length, etc. This makes numeral an important aspect of any linguistic system (Omachonu 2011). It is a known fact that majority of the world's languages are in danger of extinction. In Nigeria, out of about 500+ languages spoken in the country, only three are regarded as the major languages, and even these three so called "major" languages are also facing the same problem(s) as the minority languages. This is because, parents no longer use their mother tongue when communicating with their children and the few ones that do, in most cases borrow the numeral from English when they want to refer to numbers. The few young people who can speak their mother tongue, do not know the counting system of their language. Hardly can they count from 1-100. This makes the study of the numeral systems of these languages imperative. This is the case of the Tangle people. Usually, Hausa ${ }^{1}$ numeral system is used in counting and or sometimes the English numerals are borrowed. It is the case as pointed out by Comrie (2005) that the numeral systems of minority languages are more endangered than the languages themselves. And these numerals are replaced by neighbouring

1 Hausa uses a decimal numeral system. The tens $(20,30,40,50,60, \ldots 90)$, according to Newman (2010), in Hausa has been replaced by Arabic numerals. 
politically and economically predominant languages, (in this case Hausa and English). According to Comrie (2006: 1):

A community encountering another community with greater numeracy may well borrow the "missing" parts of its system from that other community, but the contact may also involve replacements of parts or all of the existing systems and can also affect languages that come into contact even where there is no great difference in numeracy, but just cultural or commercial superiority of one group over the other.

Since language is not just a medium of communication but also that of passing the cultural norms of a society from one generation to another, it is important that the counting concepts of human languages be preserved as well noting the fact that we cannot do away with it in our linguistic discourse.

This present study is to analyse the numeral system of Po Tangle, one of the minority languages spoken in north eastern Nigeria. The study is based on the syntax of cardinal numbers of this numeral system using the packing strategy. We shall examine the basic and complex numerals in the language and see the syntactic phenomena of complementation and coordination that come into play and how these numerals are accounted for within the packing strategy. The standard orthography by Tadi \& Zakayo (2008) is used in our presentation of data.

The paper is structured as follows; in the remainder of the introduction, a background on the Po Tangle language is provided. Section 2 examines the basic, non-basic, and complex numbers of Po Tangle. An argument in favour of the fact that numerals are actually syntactic constructions rather than morphological is the focus of section 3. In section 4, an overview of the packing strategy, the framework adopted for this study is given. Section 5 applies the assumptions of the packing strategy in analysing Po 
38 The Syntax of Po Tangle Numerals

Tangle numeral data. Section 6 concludes.

\subsection{Po Tangle}

Po Tangle belongs to the Chadic phylum of the Afro-Asiatic language family (Crozier \& Blench 1992). The language is one of the minority languages in Nigeria. Speakers of Po Tangle are located in Akko, Billiri, Kaltungo and Shongom Local Government Areas of Gombe State. The speakers inhabiting the present Kaltungo and Shongom Local Government Areas are known as the Eastern Tangle, while those in present Akko and Billiri Local Government Areas are known as Western Tangle. Tadi \& Zakayo (2008) note that major dialectal differences exist between these speech communities.

There are about six dialects of the Western Tangle, namely Tangaltong, Banganje, Tanglang, Tal, Todi, and Kalmai. The differences are both on the phonological and semantic levels but the dialects are becoming mutually intelligible (ibid.). Some writers and speakers of the language refer to it as 'Tangle,' but Po Tangle is the term the Tangle people use to designate their language. The Tangle people never refer to their language or any language as just Tangle, Hausa, or Igbo but prefix it with the word Po. The 'Tangale' spelling was actually a coinage of Hausa speakers who inserted the low mid vowel /a/ to break the consonant cluster of the voiced velar stop $/ \mathrm{g} /$ and the alveolar lateral /1/ (ibid.: 2).

Scholars such as Jungraithmayr (1991) worked on the aspects of the grammar of the language and came up with the dictionary of the language based on the Kaltungo dialect. Kure (1988) revised the alphabet developed by Hall (1944) in his Teach Yourself the Tangale Language. Tadi \& Zakayo (2008) remark that Kure's work marked a major beginning of the standardization of Po Tangle orthography, which they further revised in NERDC's Orthography of Nigerian Languages. Kidda (1993) examined the 
phonology of the language. Tadi \& Zakayo (2012) went further and developed a bilingual dictionary and vocabulary for the language.

In this work, I adopted the term 'Po Tangle,' since the work of the modern linguist is to describe and not to prescribe languages as used by native speakers. The dialect of the language spoken in Billiri, headquarter of Billiri Local Government Area (LGA) is used.

Po Tangle is a tone language with two major register tones, high and low. Lexical items in Po Tangle display both open and close word-final syllabic structures. The current orthography of the language is based on that of Tadi \& Zakayo (2008) which consists of nine vowel sounds, four diphthongs and twenty-eight consonant sounds. The language is an analytic language exhibiting few synthetic behaviors. A basic declarative sentence in Po Tangle has an SVO word order, that is, the subject precedes the verb while the object comes after the verb.

\section{Numbers in Po Tangle}

For this present study, we shall limit our numbers from 1-1,000. There is no word for million in the language. This is normally borrowed from English. Po Tangle has a decimal numeral system. The decimal system is the most common numeral system found in the world's languages. Some of the features of a decimal numeral system include:

- Single words for 1-10

- Use of addition to 10 for 11-19

- Use of multiplication by 10 (and addition) for 20-99

- Single words for higher bases, typically 100 and 1,000

In Po Tangle, there are mono-morphemic expressing the basic 
numeral 1-10. The higher numbers are expressed with the use of multiplication in base ten and addition. The higher bases make use of exponentiation of the base ten.

\subsection{Basic Numerals}

These are the simple numerals that are usually composed of a single morpheme. The natural hypothesis is that complex numerals are derived from them. The basic numerals are the numbers one to ten. These are:

$\begin{array}{ll}\text { (1) dọk } & \text { 'one' } \\ \text { rap } & \text { 'two' } \\ \text { kunung } & \text { 'three' } \\ \text { padau } & \text { 'four' } \\ \text { puwad } & \text { 'five' } \\ \text { payindi } & \text { 'six' } \\ \text { pelau } & \text { 'seven' } \\ \text { parpada } & \text { 'eight' } \\ \text { lambuda } & \text { 'nine' } \\ \text { gbọmọ } & \text { 'ten' }\end{array}$

The numeral eight appears to be bi-morphemic indicating the pattern of $(2 \times 4)$. We cannot really say if that is the case because the pattern is not found anywhere else, and there are no other instances of binary or quaternary system in the language. The pattern might as well experienced phonological erosion or modification to arrive at what is in use now.

\subsection{Non-Basic Numerals}

The numerals 11-19 are expressed syntactically by combining the numeral 10 and the basic numerals 1-9. These two are joined 
together with the addictive particle salai.

(2) gbọmọ salai dọk gbọmọ salai rap gbọmọ salai kunung gbọmọ salai padau gbọmọ salai puwad gbọmọ salai payindi gbọmọ salai pelau gbọmọ salai parpada gbọmọ salai lambuda 'eleven'

'twelve'

'thirteen'

'fourteen'

'fifteen'

'sixteen'

'seventeen'

'eighteen'

'nineteen'

In the above compound numerals 11-19, the word 'gbọmọ' can be omitted. The numeral eleven can simply be uttered as salai dok. This is also the case in Hausa where the same numeral can be uttered as sha daya instead of goma sha daya. This is only possible for numerals 11-19.

\subsection{Complex Numerals}

The non-basic numerals are also referred to as complex numerals. But in this study, we shall use the term to refer to numerals 20-1,000. The base of ten called $k w i$ is used for numerals from 20-90. The numerals $2-9$ are multiplied by the base.

(3) kwi rap 'twenty'

kwi kunung 'thirty'

kwi padau 'forty'

kwi puwad 'fifty'

kwi payindi 'sixty'

kwi pelau 'seventy'

kwi parpada 'eighty'

kwi lambuda 'ninety' 
It is noticed that there is a completely different phonological form for the basic numeral 10 and the word for base ten in (3). There is no formal resemblance, but $k w i$ is nonetheless reasonably consistent in the expression of the tens.

The numerals 21-29 are expressed thus:

(4) kwi rap salai dọk

$$
\begin{array}{ll}
\text { kwi rap salai dọk } & \text { 'twenty-one' } \\
\text { kwi rap salai rap } & \text { 'twenty-two' } \\
\text { kwi rap salai kunung } & \text { 'twenty-three' } \\
\text { kwi rap salai padau } & \text { 'twenty-four' } \\
\text { kwi rap salai puwad } & \text { 'twenty-five' } \\
\text { kwi rap salai payindi } & \text { 'twenty-six' } \\
\text { kwi rap salai pelau } & \text { 'twenty-seven' } \\
\text { kwi rap salai parpada } & \text { 'twenty-eight' }
\end{array}
$$$$
\text { kwi rap salai kunung 'twenty-three' }
$$$$
\text { kwi rap salai puwad 'twenty-five' }
$$$$
\text { kwi rap salai pelau 'twenty-seven' }
$$$$
\text { kwi rap salai lambuda 'twenty-nine' }
$$

The pattern is similar for $31-39,41-49,51-59, \ldots$. . 91-99.

The term won is used to express hundred in the language. Thousand is expressed with lakikintham. We can have numerals such as:

(5) won kunung

won lambuda

lakikintham puwad

lakikintham padau 'three hundred'

'nine hundred'

'five thousand'

'four thousand'

In complex numerals such as those composed of hundred and thousand with other non-basic numerals, there is the use of $\boldsymbol{k a}$ 'and' to indicate the coordination. The number five hundred and forty six is expressed thus:

(6) won puwad ka kwi padau salai payindi hundred five and tens four and six
$(100 \times 5)$
$+(10 \times 4)$
$+\quad 6=546$ 
The number two thousand three hundred and eighty seven is:

(7) lakikintham rap ka won kunung ka kwi parpada salai pelau thousand two and hundred three and tens eight and seven $(1,000 \times 2)+(100 \times 3)+(10 \times 8)+7=2,387$

\section{Numerals as Syntax Rather than Morphology}

On the need for numeral expressions to be regarded as syntactic constructions, rather than (sometimes by) words, perhaps compounds, formed by morphological rules, Hurford (2007: 777) notes that in some languages, the syntactic status of numerals is very clear, in that non-numeral expressions can be intercalated into their interior. In some languages, we find instances of morphology in the numeral than syntax. In English for instance, we find relatively minor morphological idiosyncrasies which can easily be identified. In the numerals thirty, forty, fifty, . . ninety, the identification of the first morphemes, that is, three, four, five, . . . nine, is more transparent than that of the second, -ty. With this, we still find instances of complementation and the use of coordinate conjunctions in English numerals such as six hundred and eighty. In Yoruba, ${ }^{2}$ it is the case that a whole phrase is brought together to form a single word.

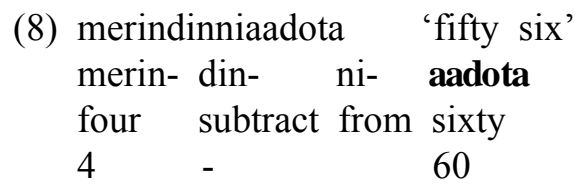

2 Yoruba is a Benue-Congo language spoken mainly in southwest Nigeria. Yoruba is one of the few languages that has numeral system with subtraction. The language uses subtraction extensively (Hurford 2001). 
In Po Tangle, there are non-numeral expressions such as $\boldsymbol{k a}$ which are intercalated into numerals as shown in examples (6) and (7) above. We shall now consider the packing strategy and how it explains the structure of the numeral in Po Tangle.

\section{The Packing Strategy}

The packing strategy is a universal constraint on numeral structures. It applies very widely to numeral systems that uses syntactic constructions to signal multiplication and addition (Hurford 2007). This constraint was propounded and developed by Hurford (1975, 1987, 2003, 2007). The packing strategy was developed within the conceptual framework of early generative grammar, and it attempts to provide rules which generate, economically and with semantic correctness, all and only the well-formed numeral expressions of a given language accounting naturally for the fact that they denote exact large numbers. Applied to numeral systems, the packing strategy amounts to providing rules which generate all and only the well-formed numeral expressions, accounting naturally for the fact that they denote exact large numbers. The goal is also to discover sets of rules which apply to all languages. The packing strategy stipulates that the value of the modifying numeral must be lower than that of the base. It is a constraint on the arithmetic combinations used in forming expressions for higher numbers.

There is a small set of phrase structure rules (PSRs) which the packing strategy works with and which are shared by all developed numeral systems. These rules are in line with the normal conventions for PSRs (Hurford 2007: 774). 
(9)

$$
\begin{aligned}
& \text { NUMBER } \rightarrow\left\{\begin{array}{l}
\text { DIGIT } \\
\text { PHRASE (NUMBER) }
\end{array}\right\} \text { (interpreted by addition) } \\
& \text { PHRASE } \rightarrow \text { (NUMBER) M (interpreted by multiplication) }
\end{aligned}
$$

'NUMBER' represents the category Numeral itself, the set of possible numeral expressions in a language; 'DIGIT' represents any single numeral word up to the value of the base number (e.g., English one, two, . . . nine); and ' $\mathrm{M}$ ' represents a category of mainly noun-like numeral forms used as multiplicational bases (e.g., English -ty, thousand, and billion). The curly brackets in the rules enclose alternatives; thus a numeral may be either a DIGIT (e.g., eight) or a PHRASE (numeral phrase) followed optionally by another numeral (e.g., eight hundred or eight hundred and eight). If a numeral has two immediate constituents (i.e., is not just a single word) the value of the whole is calculated by adding the values of the constituents; thus sixty-four means $60+4$. If a numeral phrase (as distinct from a numeral) has two immediate constituents the value of the whole is calculated by multiplying the values of the constituents; thus two hundred means $2 \times 100$ (Hurford 2001). Hurford (ibid.: 10759) defines the packing strategy thus:

within any part of a numeral structure, the sister of a NUMBER must have the highest possible value

The tree diagrams below show the structures of some complex numerals. 
(10) a.

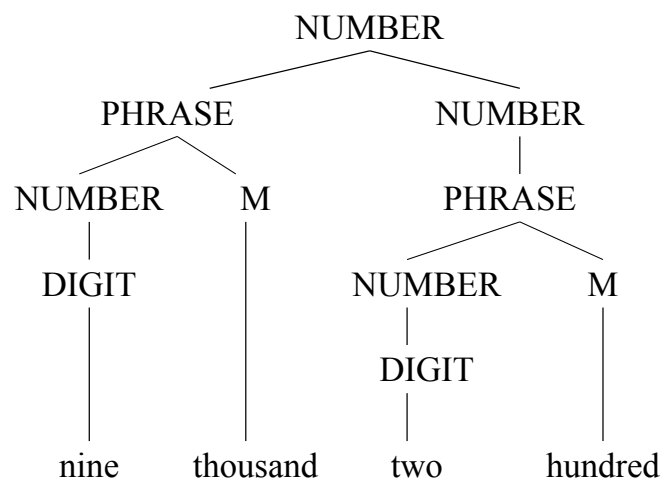

b.

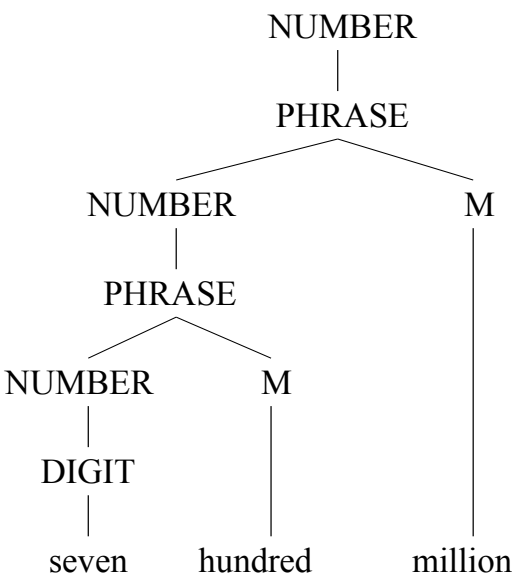

\section{Application of Packing Strategy to Po Tangle Numerals}

DIGIT is the category of basic lexical numerals such as English one, two, three, . . . nine. This is the case of Po Tangle's dok 'one' to lambuda 'nine' as in subsection 2.1. M (multiplier) is the category of multiplicative base morphemes, such as English -ty, 
hundred, thousand, million, etc. In Po Tangle, we only have the following three: kwi 'tens,' won 'hundreds,' and lakikintham 'thousands.' The semantic interpretations, addition, and multiplication are only applicable where two constituents are chosen. A numeral can either be a DIGIT or a PHRASE and a NUMBER in which case is interpreted by addition. If it is not a single word as in DIGIT, the value of the whole is calculated by adding the values of the constituents: thus, kwi parpada salai pelau ' 87 ' means 80 +7 . If a phrase has immediate constituents, the value of the whole is calculated by multiplying the values of the constituents: thus won lambuda '900' means $100 \times 9$.

The numeral won lambuda '900' which is a PHRASE is interpreted by multiplication and the $\mathrm{M}$ won 'hundred' has a higher value in the phrase than the NUMBER lambuda 'nine.' The numeral kwi parpada salai pelau ' 87 ' is a combination of a PHRASE, kwi parpada '80' and a NUMBER, pelau '7.' The phrase in the above numeral is composed of an $\mathrm{M}, k w i$ 'tens' and a NUMBER, parpada ' 8 ,' thus $M$ which is a sister constituent of NUMBER has a higher value and the whole PHRASE kwi parpada ' 80 ' has the highest possible value in the numeral $k w i$ parpada salai pelau.

(11) a.

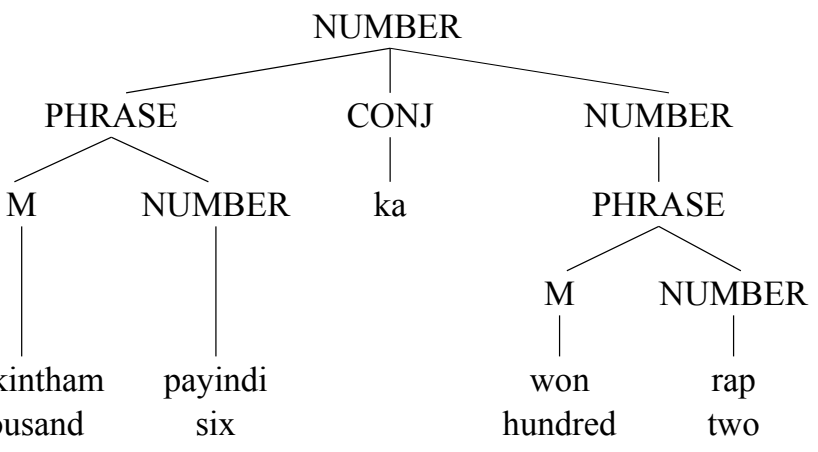

'six thousand two hundred' $=6,200$ 
b.

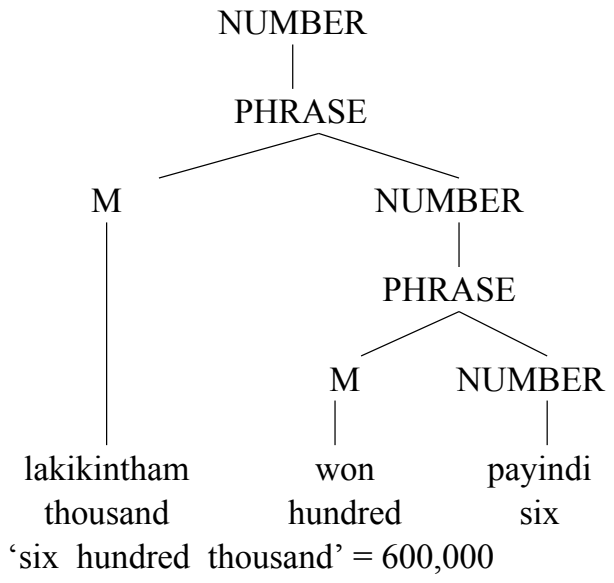

The structure in (11a) is an additive construction this means that it is interpreted by addition. The PHRASE lakikintham payindi 'six thousand' has a higher value than its sister constituent NUMBER. In (11b), we have a multiplicative construction. The two bases (M) in the construction are higher than the DIGIT payindi 'six.' The $\mathrm{M}$ that immediately precedes this digit, won has the value hundred, but it is not the highest-valued one, there is lakikintham 'thousand.' The packing strategy insists that well-formed numeral structures "pack" the highest-valued constituents in at the highest structural level. Constituents of the category of NUMBER are interpreted by addition, and those of the category of PHRASE by multiplication.

\subsection{The Connectives}

Hurford (2003: 41) postulates that all languages with numeral system use addition and multiplication as the principal semantic (arithmetic) operations for the construction of complex numerals. Languages make use of particles denoting addition, and less often 
multiplication. According to Ionin \& Matushansky (2006), markers of arithmetic operation for addition are usually conjunction and adposition such as English and, French et, Hausa $d a$, and Igbo $n a$ as shown below.

(12) a. five hundred and eight $=508$ (English)

b. vingt- et- un $=21$

(French) twenty and one

'twenty one'

c. ashirin da bakwai $=27$ (Hausa) twenty and seven 'twenty seven'

d. iri ato na ise $=35 \quad$ (Igbo) ten three and five 'thirty five'

e. tri ar $\operatorname{ddeg}=27$

three on ten 'thirteen' (Hurford 2003)

The use of conjunction and adposition can be seen in the above examples. There are usually no overt marking for the arithmetic operation of multiplication.

Addition in Po tangle is signalled explicitly by the overt connectives salai and ka. Salai is used for numerals below hundred (see data (2) and (4) above), while $k a$ is used with higher numerals of bases hundred and thousand. 
(13) a. lakikintham padau ka won puwad ka thousand four CONJ hundred five CONJ kwi pelau salai rap ten seven CONJ two

'four thousand five hundred and seventy-two' $=4,572$

b. won rap $\mathrm{ka}$ lambuda

hundred two CONJ nine

'two hundred and nine' $=209$

c. won dọk ka kwi parpada salai lambuda hundred one CONJ ten eight CONJ nine 'one hundred and eighty-nine' $=189$

(14)

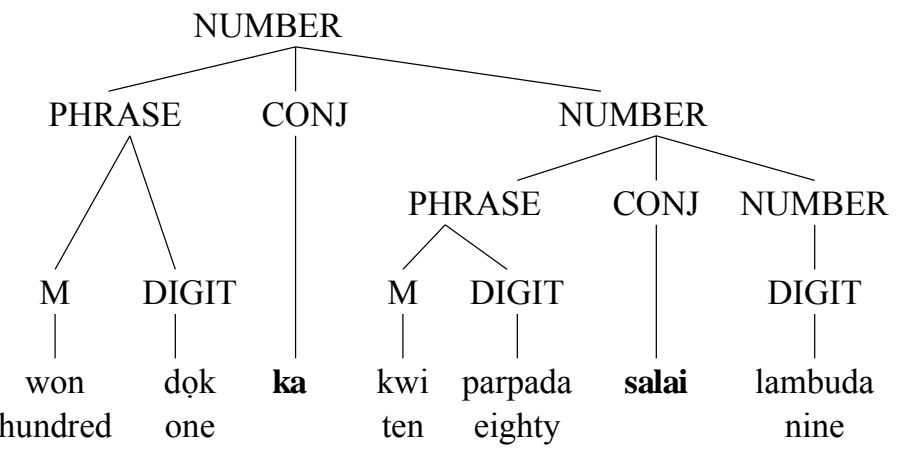

'one hundred and eighty-nine' $=189$

The numeral structure in (14) represents the numeral phrase in (13c), where the two connectives found in the language under study are exemplified. 
Mary Chimaobi Amaechi 51

\section{Conclusions}

This paper has examined the simple and complex cardinal numerals in Po Tangle, a Chadic language spoken in north eastern Nigeria. The study has been on the syntax of the numeral structures of the language using Hurford's principle of packing strategy which attempts to provide rules which generate, economically and with semantic correctness, all and only the well-formed numeral expressions of a given language. Po Tangle has a decimal numeral system. The language's complex numerals are arrived at through coordination and multiplication. Two addictive particles are found in the language, one for numerals below hundred, salai, and the other for hundred and thousand, $k a$. It is recommended that further studies should be carried out in the aspect of semantics of these numeral structures and also on the ordinal numerals. Researchers on the numeral systems of the other languages are also encouraged so that these dying numbers can be revived and in doing this, we are also in some way reviving the languages themselves.

\section{References}

Comrie, B. 2005. Numeral Bases. In M. Haspelmath et al. (eds.), The World Atlas of Language Structures 530-533. Oxford: Oxford University Press.

. 2006. Endangered Numeral Systems. Paper presented at

Max Planck Institute for Evolutionary Anthropology. Leipzig. Crozier, D. \& R. Blench. 1992. An Index of Nigerian Languages. Dallas, TX: SIL.

Hall, J. 1944. From Cannibalism to Christ: A Study of the Transforming Power of the Gospel in Darkest Africa. Toronto: Evangelical Publishers. 
52 The Syntax of Po Tangle Numerals

Hurford, J. 1975. The Linguistic Theory of Numerals. Cambridge: Cambridge University Press. . 1987. Language and Number: The Emergence of a Cognitive System. Oxford: Blackwell. . 2001. Numeral Systems. In N. Smelser \& P. Baltes (eds.), International Encyclopedia of the Social and Behavioural Sciences 10756-10761. Amsterdam: Pergamon. 2003. The Interaction between Numerals and Nouns. In F. Plank (ed.), Noun Phrase Structure in the Languages of Europe 561-620. Mouton de Gruyter: The Hague. . 2007. A Performed Practice Explains a Linguistic Universal: Counting Gives the Packing Strategy. Lingua 117, 773-783.

Jungaithmayr, H. 1991. A Dictionary of the Tangale Language (Kaltungo, Northern Nigeria). Berlin: Dietrich Reimer Verlag. Ionin, T. \& O. Matushansky. 2006. The Composition of Complex Cardinals. Journal of Semantics 23, 315-360.

Kidda, M. 1993. Tangale Phonology: A Descriptive Analysis. Berlin: Dietrich Reimer Verlag.

Kure, S. 1988. Teach Yourself the Tangale Language. Jos: Challenge Press.

Newman, P. 2010. Hausa. Available at URL $<\mathrm{http}$ ://lingweb.eva.mpg.de/numeral/>.

Omachonu, G. 2011. Derivational Process in Igala Numeral System: Some Universal Considerations. Journal of Universal Language 12.2, 81-101.

Tadi, N. \& M. Zakayo. 2008. Po Tangle Orthography. Lagos: NERDC Press.

2012. Wunthu Sab Tangle: Po Tangle-English Dictionary and Vocabulary. Zaria: Ahmadu Bello University Press. 


\section{APPENDIX}

\section{Po Tangle Numerals}

1 - dọk

2 - rap

3 - kunung

4 - padau

5 - puwad

6 - payindi

7 - pelau

8 - parpada

9 - lambuda

10 - gbọmọ

11 - gbọmọ salai dọk

12 - gbọmọ salai rap

13 - gbọmọ salai kunung

14 - gbọmọ salai padau

15 - gbọmọ salai puwad

16 - gbọmọ salai payindi

17 - gbọmọ salai pelau

18 - gbọmọ salai parpada

19 - gbọmọ salai lambuda

20 - kwi rap

21 - kwi rap salai dọk

22 - kwi rap salai rap

23 - kwi rap salai kunung

24 - kwi rap salai padau

25 - kwi rap salai puwad

26 - kwi rap salai payindi

27 - kwi rap salai pelau

28 - kwi rap salai parpada

29 - kwi rap salai lambuda

30 - kwi kunung 
54 The Syntax of Po Tangle Numerals

40 - kwi padau

50 - kwi puwad

60 - kwi payindi

70 - kwi pelau

80 - kwi parpada

90 - kwi lambuda

100 - won dọk

200 - won rap

300 - won kunung

400 - won padau

500 - won puwad

600 - won payindi

700 - won pelau

800 - won parpada

900 - won lambuda

1,000 - lakikintham dọk

101 - won dọk ka dọk

121 - won dọk ka kwi rap salai dọk

1,001 - lakikintham dọk ka dọk

1,346 - lakikintham dọk ka won kunung ka kwi padau salai payindi 